\title{
Meningioma in pregnancy and perinatal outcomes
}

\author{
Astrit M. Gashi, Jakup Ismajli, Curr Gjocaj, Atdhe Keqa, Visare Batalli, Qefsere Mulaj
}

Department of Obstetrics and Gynecology, University Clinical Centre of Kosovo, Pristine

\begin{abstract}
A pregnancy is categorized as with high-risk when the mother is diagnosed with any tumor in the brain. Meningiomas are tumors that take origin from the arachnoid villi and produce a globoid or discoid mass. Meningiomas account for approximately 38 percent of all intracranial tumors in females and 20 percent in males. They are usually localized in parasagittal areas, convexities of the cerebral hemispheres, the olfactory groove, and the lateral wing of the sphenoid. Most meningiomas are diagnosed in women between 30 and 50 years old. For meningiomas diagnosis are used: MRI, CT, and very rarely angiography. Tumors in the brain can be typical or benign, atypical, anaplastic or malignant. $88-94 \%$ of meningiomas are benign tumors. During pregnancy, MRI is most recommended for the diag-nosis and evaluation of brain meningiomas. We report the management of a 26-yearold woman patient diagnosed with olfactory groove meningioma, who has been subjected to one bifrontal craniotomy and gross total resection (GTR) (Simpson grades I/II), on week 33 of gestation, without any complications as during surgery that lasted 6 hours, as well as during pregnancy and childbirth.
\end{abstract}

Keywords: pregnancy, meningioma, management, perinatal outcomes

\section{INTRODUCTION}

Meningiomas are tumors that take origin from the arachnoid villi and produce a globoid or discoid mass. Meningiomas account for approximately 38 percent of all intracranial tumors in females and 20 percent in males (1). So, they are more common in women than in men. Although meningiomas may occur at almost any intracranial site, they are most common in parasagittal areas, convexities of the cerebral hemispheres, the olfactory groove, and the lateral wing of the sphenoid. Most meningiomas are diagnosed in women between 30 and 50 years old (2-6). For meningiomas diagnosis are used; MRI, CT, and very rarely angiography. MRI is most recommended for the diagnosis and evaluation of brain meningiomas (7-10).

The World Health Organization (WHO) classifies meningiomas into 15 subtypes under 3 major categories:

- Grade 1 (typical or benign), representing $88-94 \%$ of cases
- Grade II (atypical), representing 5-7\% of cases

- Grade III (anaplastic or malignant), representing $1-2 \%$ of cases

The cause of meningioma is not completely understood, but there are some risk factors as: receiving radiation therapy, patients who have neurofibromatosis type 2, a rare, inherited (genetic) nervous system disorder. People with neurofibromatosis type 2 often get benign tumors of the nerves throughout the body. We report the management of a patient diagnosed with olfactory groove meningioma, of benign nature, with very good perinatal outcomes.

\section{CASE PRESENTATION}

The 26-year-old G3P2L2 with 32 completed weeks of gestation was presented in a private obstetric clinic with continuous headaches, nausea, persistent vomiting for three weeks, loss of smell 
(anosmia), with changes in vision, such as seeing double or blurriness, with three episodes of seizures in the last week, mild difficulty with memory, euphoria and diminished concentration. In the general appearance, the patient was pallor, weary, slightly edematous, with body mass index (BMI):33, blood pressure 110/70 $\mathrm{mmHg}$, heart rate; $90 \mathrm{bpm}$. SpO2; 97\%, no proteinuria, uterine fundus height and fetal movements were within normal limit. Her routine hematological and biochemical parameters were within normal limit. The woman declares that there was no surgical history in the past such as cardiac surgery, cesarean section, myomectomy, cone biopsy of the cervix, etc. Also, she declares she does not smoke and does not consume alcohol or drugs.

In the previous medical history, there was no allergy to penicillin, or illnesses such as; diabetes, epilepsy, hypertension, renal disease, rheumatic disease, heart valve disease, epilepsy, asthma, tuberculosis, psychiatric illness or any other significant illness. She had taken $\mathrm{Rh}$ immune globulins on the 28th week of pregnancy. She had two spontaneous vaginal deliveries, at term. There is no history of complications during previous pregnancy. No specific finding is observed on abdominal and vaginal examination. An ultrasound examination was performed; fetal biometry responds to week 32 of pregnancy, cephalic presentation, and anterior placental localization. The amniotic fluid index (AFI) was $14 \mathrm{~cm}$. Normal fetal movements. The fetal heart rate is 142 beats per minute. Based on clinical findings, the patient is recommended the MRI of the brain. MRI brain showed olfactory groove meningioma. We have presented on three plans MRI of the brain with olfactory groove meningioma, before and after surgery (Figure 1, 2, 3).

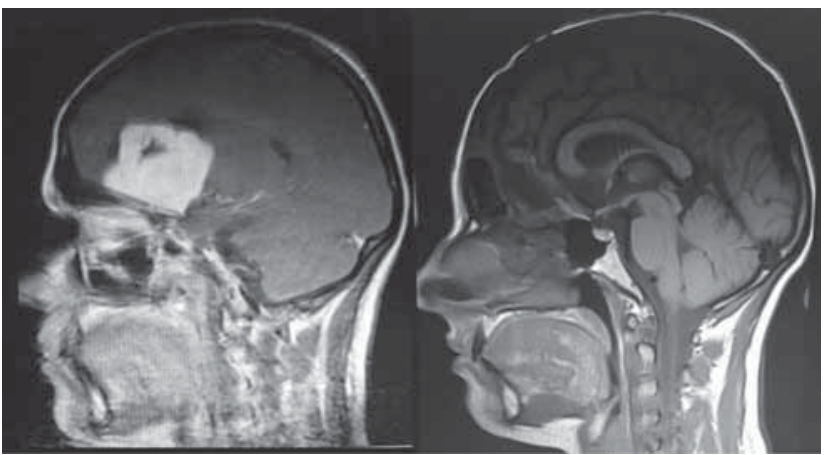

FIGURE 1. MRI of the brain, sagittal plane; olfactory groove meningioma, before and after surgery.

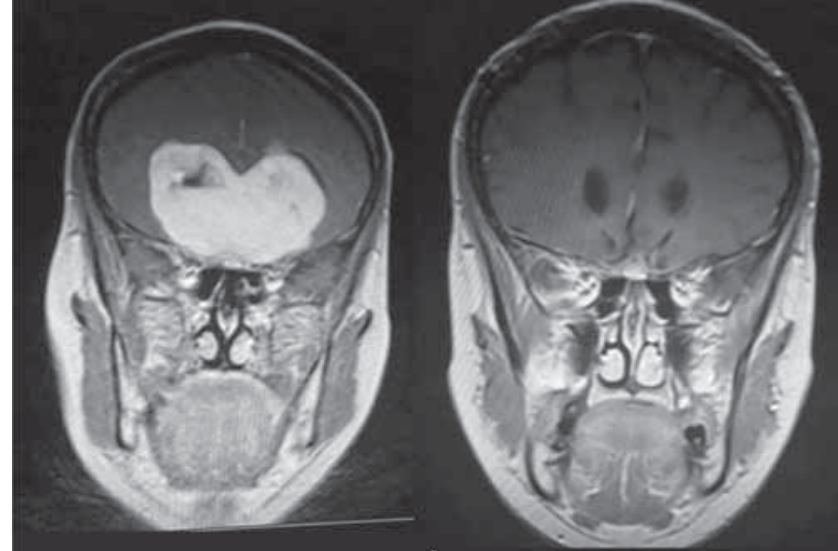

FIGURE 2. MRI of the brain, coronal plane; olfactory groove meningioma, before and after surgery.

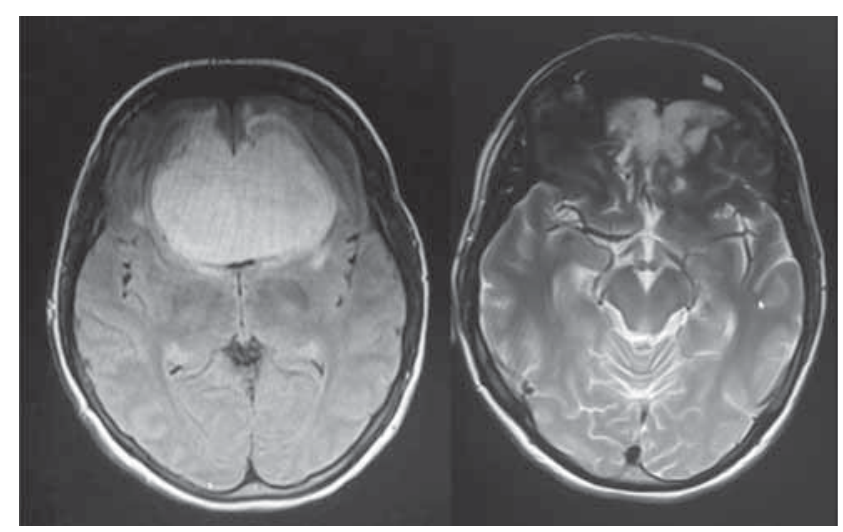

FIGURE 3. MRI of the brain, axial plane; olfactory groove meningioma, before and after surgery.

Also, MRI clearly defines the extent of the tumor, the edema in the surrounding brain, the relationship of the optic nerves and anterior cerebral arteries. Angiography was not needed. The indications for emergency surgical treatment have been the presence of severe neurological symptoms. A week later she underwent an operational intervention, respectively a bifrontal craniotomy and gross total resection (GTR) (Simpson grades I/II). Operation lasted 6 hours; the patient had none of the perioperative complications. The patient releases the clinic in a very good health condition after a week with adequate counseling and therapy. Five weeks later, at 38 weeks' gestation presents to labor and delivery with uterine contractions, and is found to be in active labor with the fetus in cephalic presentation. The cervix is $7 \mathrm{~cm}$ dilated, $100 \%$ effaced and the fetal head is at zero station. She has had an uncomplicated antepartum course with good prenatal care including a normal anatomy scan in the second trimester. Ultrasound evaluation shows a fetal weight (EFW) approximately 3200 gram, cephalic 
presentation, and clinical assessment of the maternal pelvis is determined to be adequate for a fetus of this estimated weight. But in co-thinking with the patient and the neurosurgeon, to avoid possible complications, it is decided that the birth ends with Cesarean section. Under general anesthesia, she was born male with body weight 3250 gram, length $52 \mathrm{~cm}$ and Apgar score 7/8. Cesarean delivery passes without complications. Four days later, the patient is released from the clinic in good health and with a healthy baby.

\section{DISCUSSIONS}

In 1937 Hagedoorn described the effect of pregnancy on intracranial meningioma (11). The signs and symptoms of a pre-existing tumor such as a meningioma can flare during gestation and improve spontaneously postpartum (12).

Most case reports show aggravation of signs and symptoms in one of the following mechanisms: (a) fluid retention, vascular engorgement, and increased edema; (b) the presence of hormone receptors on tumor cells (as estrogen receptors and especially progesterone receptors), leading to dramatic growth of meningioma during pregnancy (13-17).

Clinical signs and symptoms of intracranial meningioma during pregnancy can be confused with hyperemesis gravidarium early in pregnancy or with eclampsia late in pregnancy or even with puerperal psychosis. However, the presence of signs and symptoms of elevated intracranial pressure as; focal seizures, changes in vision, lateralizing neurological deficits, abnormal funduscopic examination suggests the diagnosis of an intracranial mass, and investigations are required with MRI to establish the diagnosis $(18,19)$.

Diagnosis of meningioma in most cases is determined only with magnetic resonance imaging of the brain. If information is needed about bone detail, computerized CT (CT) is done. Angiography is rarely needed, only when more information is needed about the arterial supply or venous drainage to plan the operation or for preoperative embolization.

The management plan of meningioma during pregnancy is individual and depends on the presence of signs and symptoms of elevated intracranial pressure. Advances in microsurgical techniques, neuroanesthesia, and noninvasive fetal monitoring (as umbilical artery Doppler velocimetry and fetal biophysical profile) have enabled safe neurosurgical management of meningioma during pregnancy. In our case, persistent headaches, nausea, persistent vomiting, loss of smell, anomalies, focal seizures, changes in vision such as seeing double or blurriness were the primary indication for urgent intervention. Although, surgery during pregnancy associates a high risk for fetus and mother. Our case there was no perioperative complications. Most studies show that cases with meningioma with slower growth can continue to full-term delivery without endangering the mother or fetus (20). But for our case, it was an urgent neurosurgical treatment due to the presence of severe neurological symptoms and a Caesarean delivery due to the short time of neurosurgical intervention both interventions were performed with very good outcomes.

\section{CONCLUSION}

Advanced developments in the field of neurosurgical intervention, neuroanesthesia and noninvasive fetal monitoring, enable safe resection of meningiomas during pregnancy, without endangering the mother of the fetus. Most pregnant with meningioma continue their pregnancy until the term without any problem. Needs for urgent neurosurgical intervention is reserved for malignancy, increased intracranial pressure, progressive neurological deficit. Delivery with Caesarean section is not the safest way of birth, but it is indicated in cases such as; prima gravida with protracted secondstage labor associated with clinical and radiological features of refractory, increased intracranial pressure, and for other fetal and maternal indications. Although, surgery during pregnancy associates a high risk for fetus and mother. Our case there was no perioperative complications.

\section{Conflict of Interests}

The authors declare that there is no conflict of interests.

\section{Ethic Committee approval:}

This case report was approved by the Ethical Committee of the Faculty of Medicine, Universi- 


\section{ty of Prishtina, and the research was conducted in accordance with the Declaration of Helsinki guidelines. Written informed consent was ob-}

tained from the patient before inclusion in the study.

\section{REFERENCES}

1. Weber DC, Lovblad KO, Rogers L. New pathology classification, imagery techniques and prospective trials for meningiomas: the future looks bright. Current opinion in neurology. $2010 \mathrm{Dec}$ 1;23(6):563-70.

2. Bigner DD, McLendon RE, Bruner JM, eds. Russell and Rubenstein's Pathology of Tumours of the Nervous System. 6th ed. New York: Oxford University Press; 1998.

3. Osborn AG. Stroke. Astrocytomas and other glial neoplasms. Diagnostic neuroradiology. 1994;345:529-43.

4. Rubinstein LJ. Tumors of the Central Nervous System. 2nd ed. Washington, DC.. Armed Forces Institute of Pathology. 1972:169-86.

5. Mehdorn HM. Intracranial meningiomas: a 30-year experience and literature review. InAdvances and technical standards in neurosurgery 2016 (pp. 139-184). Springer, Cham.

6. Baldi I, Engelhardt J, Bonnet C, Bauchet L, Berteaud E, Grüber A, Loiseau H. Epidemiology of meningiomas. Neurochirurgie. 2014 Sep 22.

7. Latini F, Larsson EM, Ryttlefors M. Rapid and Accurate MRI Segmentation of Peritumoral Brain Edema in Meningiomas. Clinical neuroradiology. 2017 Jun 1;27(2):145-52.

8. Surov A, Ginat DT, Sanverdi E, Lim CT, Hakyemez B, Yogi A, Cabada $T$, Wienke A. Use of Diffusion Weighted Imaging in Differentiating Between Maligant and Benign Meningiomas. A Multicenter Analysis. World neurosurgery. 2016 Apr 1;88:598-602.

9. Ali R, Khan M, Chang V, Narang J, Jain R, Marin H, Rock J, Kole M. MRI Pre-and Post-Embolization Enhancement Patterns Predict Surgical Outcomes in Intracranial Meningiomas. Journal of Neuroimaging. 2016 Jan 1;26(1):130-5.

10. Tan LA, Boco T, Johnson AK, Rivas FF, Ahmed S, Byrd SE, Byrne RW. Magnetic resonance imaging characteristics of typical and atypical/anaplastic meningiomas - Case series and literature review. British journal of neurosurgery. 2015 Jan 2;29(1):77-81.

11. Hagedoorn A. The chiasmal syndrome and retrobulbar neuritis in pregnancy. American Journal of Ophthalmology. $1937 \mathrm{Jul}$ 1;20(7):690-9.

12. Cushing H, Eisenhardt L. Their Classification, Regional Behavior, Life History, and Surgical End Results: The chiasmal syndrome. Meningiomas. Suprasellar Meningiomas. 1938:224-49.

13. Bickerstaff ER, Small JM, Guest IA. The relapsing course of certain meningiomas in relation to pregnancy and menstruation. Journal of neurology, neurosurgery, and psychiatry. 1958 May;21(2):89.

14. Cahill DW, Bashirelahi N, Solomon LW, Dalton T, Salcman M, Ducker TB. Estrogen and progesterone receptors in meningiomas. Journal of neurosurgery. 1984 May;60(5):985-93.

15. Schrell UM, Adams EF, Fahlbusch R, Greb R, Jirikowski G, Prior R, Ramalho-Ortigao FJ. Hormonal dependency of cerebral meningiomas: Part 1: Female sex steroid receptors and their significance as specific markers for adjuvant medical therapy. Journal of neurosurgery. 1990 Nov;73(5):743-9.

16. Tilzer LL, Plapp FV, Evans JP, Stone D, Alward K. Steroid receptor proteins in human meningiomas. Cancer. 1982 Feb 15;49(4):633-6.

17. Kanaan I, Jallu A, Kanaan H. Management strategy for meningioma in pregnancy: a clinical study. Skull Base. 2003;13(04):197-204.

18. Sahu S, Lata I, Gupta D. Management of pregnant female with meningioma for craniotomy. Journal of neurosciences in rural practice. 2010 Jan;1(1):35.

19. Lucy D, Pratima M, Puspa K, Umakant S, Niharika P. Pregnancy with meningioma. J Obstet Gynecol India. 2008 Mar;58(2):156-8.

20. Keating RF. Brain tumors. Philadelphia, PA: Lippincott Williams \& Wilkins. 2000:547-533. In: Cohen WR, ed. Cherry \& Merkatz's Complications of Pregnancy 5th Edition. 